\title{
Anesthesia-Associated Relative Hypovolemia: Mechanisms, Monitoring, and Treatment Considerations
}

\author{
Jessica Noel-Morgan ${ }^{1 \star}$ and William W. Muir ${ }^{2,3}$ \\ 'Center for Cardiovascular \& Pulmonary Research, The Research Institute at Nationwide Children's Hospital, Columbus, OH, \\ United States, ${ }^{2}$ QTest Labs, Columbus, OH, United States, ${ }^{3}$ College of Veterinary Medicine, Lincoln Memorial University, \\ Harrogate, TN, United States
}

OPEN ACCESS

Edited by:

Keila Ida,

University of Liège, Belgium

Reviewed by:

Olivier Levionnois,

University of Bern, Switzerland

Rene Doerfelt,

LMU Munich, Germany

*Correspondence: Jessica Noel-Morgan

morgan.net@icloud.com

Specialty section: This article was submitted to Veterinary Surgery and Anesthesiology,

a section of the journal Frontiers in Veterinary Science

Received: 15 December 2017 Accepted: 02 March 2018

Published: 16 March 2018

Citation:

Noel-Morgan J and Muir WW (2018) Anesthesia-Associated Relative Hypovolemia: Mechanisms, Monitoring, and Treatment Considerations.

Front. Vet. Sci. 5:53.

doi: 10.3389/fvets.2018.00053
Although the utility and benefits of anesthesia and analgesia are irrefutable, their practice is not void of risks. Almost all drugs that produce anesthesia endanger cardiovascular stability by producing dose-dependent impairment of cardiac function, vascular reactivity, and compensatory autoregulatory responses. Whereas anesthesia-related depression of cardiac performance and arterial vasodilation are well recognized adverse effects contributing to anesthetic risk, far less emphasis has been placed on effects impacting venous physiology and venous return. The venous circulation, containing about $65-70 \%$ of the total blood volume, is a pivotal contributor to stroke volume and cardiac output. Vasodilation, particularly venodilation, is the primary cause of relative hypovolemia produced by anesthetic drugs and is often associated with increased venous compliance, decreased venous return, and reduced response to vasoactive substances. Depending on factors such as patient status and monitoring, a state of relative hypovolemia may remain clinically undetected, with impending consequences owing to impaired oxygen delivery and tissue perfusion. Concurrent processes related to comorbidities, hypothermia, inflammation, trauma, sepsis, or other causes of hemodynamic or metabolic compromise, may further exacerbate the condition. Despite scientific and technological advances, clinical monitoring and treatment of relative hypovolemia still pose relevant challenges to the anesthesiologist. This short perspective seeks to define relative hypovolemia, describe the venous system's role in supporting normal cardiovascular function, characterize effects of anesthetic drugs on venous physiology, and address current considerations and challenges for monitoring and treatment of relative hypovolemia, with focus on insights for future therapies.

Keywords: relative hypovolemia, distributive shock, mean circulatory filling pressure, anesthesia, fluid therapy, functional hemodynamics, dynamic index, preload responsiveness

\footnotetext{
Abbreviations: CO, cardiac output; CVCDI, caudal vena cava distensibility index; CVP, central venous pressure; $\Delta$ Vpeak, aortic flow peak velocity variation; DO2, oxygen delivery; $\mathrm{HR}$, heart rate; iNOS, inducible nitric oxide; $\mathrm{K}_{\mathrm{ATP}}$ channels, ATPsensitive potassium channels; LiDCO, lithium dilution cardiac output; MCFP, mean circulatory filling pressure; MSP, mean systemic pressure; $\mathrm{MV}$, mechanical ventilation; PAC, pulmonary artery catheter; $\mathrm{PPV}$, pulse pressure variation; $\mathrm{Pv}-\mathrm{aCO}$, venoarterial difference in $\mathrm{PCO} 2$; $\mathrm{RV}$, right ventricle; $\mathrm{SPV}$, systolic pressure variation; $\mathrm{SV}$, stroke volume; $\mathrm{ScvO}$ 2, central venous oxygen saturation; $\mathrm{SvO} 2$, mixed venous oxygen saturation; SVV, stroke volume variation; Vs, stressed circulating blood volume; Vt, tidal volume; Vus, unstressed intravascular volume; VVC, venous vascular capacitance.
} 


\section{INTRODUCTION}

To survive anesthesia is to survive a potentially life-threatening event. What other form of medical practice is designed to intentionally depress or inhibit a spectrum of neurophysiologic processes so as to be able to painlessly inflict varying degrees of medical or surgical psychological or physical trauma. Although the potential benefits and utility of anesthesia and analgesia are obvious, the practice of anesthesia is not without risk, particularly in animals. Indeed, the adverse events associated with anesthetizing animals, although similar to those reported in humans, are far more common than reported for humans (1-4). A recent study investigating adverse events associated with anesthesia in dogs and cats suggested that approximately $40 \%$ of animals had at least one adverse event and as many as $1 \%$ had up to six adverse events (5). Anesthetic death is reported to occur in approximately $0.5,1.0$, and 10 in every 1,000 anesthetic episodes in otherwise healthy dogs, cats, and horses, respectively (6-10). These rates are two to three orders of magnitude greater than those reported for healthy humans (approximately 0.001 per 1,000$)$ (1). Among the many potential explanations for this discrepancy, human error, inadequate training, lack of experience or familiarity with the drugs and equipment used to produce anesthesia, insufficient monitoring, and haste or distraction, have been identified as specific causes for adverse outcomes in human medicine (3). Species differences aside, the incidence of adverse events, including intraoperative cardiac arrest, is considerably greater in animals than in humans $(2,8,9,11)$. Reemergence from anesthesia, breakthrough pain, hypoventilation, respiratory arrest, airway complications, and hypotension are comparatively common adverse events reported in dogs, cats, and horses $(5,8,10,11)$. Anesthesiaassociated hypotension is frequently attributed to a decrease in ventricular contractile performance, arterial vasodilation, or both $(5,10-14)$. Far less emphasis has been placed upon alterations in venous physiology or the effects of anesthetic drugs on the venous system's contribution to cardiac output (CO). Increasing evidence, however, suggests that anesthetic drugs produce significant and clinically relevant effects on venous function that result in increases in venous capacitance and compliance, and a reduced response to vasoactive substances (15-17). Anesthetic drug impairment of venous function is an insidious and relatively unappreciated cause of relative hypovolemia that reduces $\mathrm{CO}$, predisposes to hypotension, and can lead to vasodilatory shock especially in sick (e.g., septic), depressed, or debilitated animals (17-19). The focus of this short perspective is to define relative hypovolemia, describe the function of the venous system and its role in maintaining normal cardiovascular function, emphasize the effects of anesthetic drugs on venous physiology, and outline considerations for monitoring and treating relative hypovolemia.

\section{VENOUS PHYSIOLOGY AND CO}

Maintenance of adequate $\mathrm{CO}$ and arterial blood pressure are dependent upon a normal blood volume, vascular tone (arterial and venous), venous return (more appropriately "venous excess"), heart rate (HR), ventricular function, and multiple autoregulatory (compensatory) mechanisms, and are vital for preserving tissue perfusion and oxygen delivery $(\mathrm{DO} 2)(15,16$, $20,21)$. Venous return is CO during steady state conditions and is modulated by central venous pressure (CVP): the heart cannot pump what it does not receive. The venous system contains $65-70 \%$ of the total blood volume and small veins and venules in the abdomen, spleen, liver, and venous plexus of the skin are more than $30 \times$ more compliant than arteries (Figure 1) $(15,22-25)$. Splanchnic and cutaneous veins contain a large population of both alpha- 1 and 2 adrenergic receptors that are highly sensitive to central nervous system sympathetic output, adjustments in baroreceptor reflex activity in response to changes in arterial blood pressure, and endogenous or exogenously administered vasoactive substances (26-29). Splanchnic venous capacitance vessels in particular are much more sensitive to a decrease in carotid sinus pressure or an increase in sympathetic nerve activity than arteries, allowing healthy non-anesthetized animals to lose up to $15-20 \%$ of their total blood volume without initiating a significant compensatory hemodynamic response, primarily owing to the reservoir response of the splanchnic veins (26). Alpha-1 adrenergic effects mediated by baroreceptor reflex adjustments contribute significantly to alterations in splanchnic venous capacity $(15,23,27,29)$. Adjustments in venous capacitance aid in maintaining an effective or "stressed" circulating blood volume [the blood volume required to produce measurable increase in transmural pressure: stressed circulating blood volume (Vs)], and are a primary determinant of venous return and therefore CO $(15,16,21,24,30,31)$. The unstressed intravascular volume (Vus) is the blood volume required to fill the circulatory system to capacity without increasing cardiovascular transmural pressure (Figure 2) $(15,23)$. The Vus is composed of a recruitable volume and a residual volume that is functionally analogous to the expiratory reserve and residual volumes that compose the functional residual capacity in the lung. The Vs comprises approximately

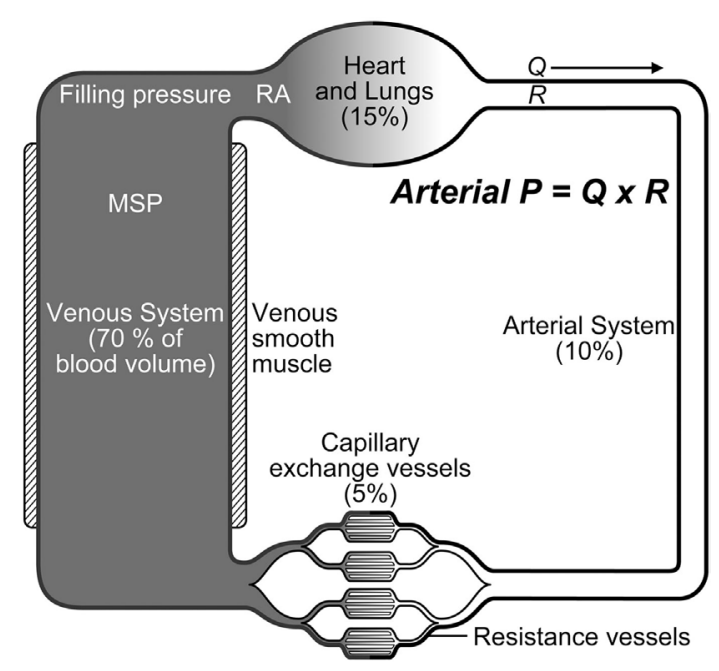

FIGURE 1 | Blood is unevenly distributed throughout the systemic circulation The large and small veins contain approximately $70 \%$ of the blood volume. Arterial pressure $(P)$ is determined by blood flow $(Q)$ and systemic vascular resistance $(\mathrm{R})$; MSP, mean systemic pressure; $R A$, right atrium. 


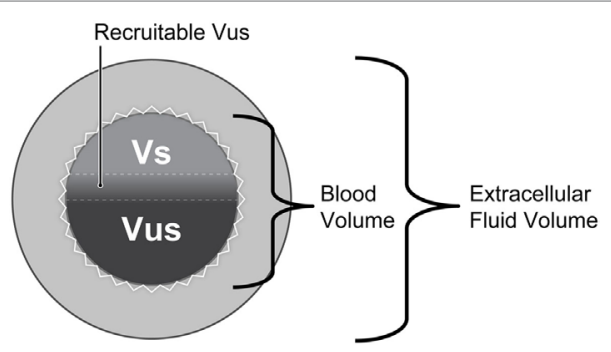

FIGURE 2 | The total blood volume within the vasculature can be divided into two components: stressed circulating blood volume (Vs: approximately 30\% of the blood volume) and unstressed intravascular volume (Vus: approximately $70 \%$ of the blood volume). The $V_{s}$ is hemodynamically active (i.e., effective circulating blood volume) and is the principal determinant of the mean systemic pressure, a primary determinant of venous return. The Vus is the volume of blood required to fill the vascular space without increasing blood pressure. A portion of the Vus (up to 15-20 mL/kg; shaded area between the dashed horizontal lines) serves as a blood reservoir and can be recruited to augment the $V_{s}$ during times of stress or replenish the $V s$ during hypovolemia. The wavy white line surrounding the inner circle (i.e., volume) suggests that the volume contained therein can become smaller or larger depending upon changes in vasomotor tone.

$30 \%$ of the predicted total blood volume $(20-25 \mathrm{~mL} / \mathrm{kg})$ in most animals, while the Vus can provide a portion of its volume (recruitable reserve volume; approx. $15-20 \mathrm{~mL} / \mathrm{kg}$ ) when maximally activated $(24,28,31)$. This volume of blood is equivalent to the administration of $45-60 \mathrm{~mL} / \mathrm{kg}$ of IV crystalloid, if it is assumed that only one-third of a crystalloid fluid bolus remains in the vascular compartment (32). Only Vs, the "effective" circulating volume, is hemodynamically active, and only a portion of Vus is available to provide a rapidly recruitable reserve volume that can be mobilized during times of need (e.g., exercise, trauma, hemorrhage).

The driving pressure for blood flow returning to the heart from peripheral veins is theorized to be determined by the pressure gradient between a proposed "pivoting pressure," termed the mean circulatory filling pressure (MCFP), and the right atrium (CVP) $(15,21,23,33-35)$. The MCFP is the equilibration pressure measured at all points in the circulation when the heart is stopped. This pressure is assumed to be located in the venous capacitance vessels, particularly the splanchnic vasculature, and is modified by the effects of both arterial baroreceptor and chemoreceptor reflex mechanisms on venous vascular compliance, and capacitance (36-38). Some consider it to be a flawed and untenable physiologic concept, although many hold the opinion that it does provide a conceptual framework for explaining how changes in venous reservoir compliance and capacitance are associated with alterations in $\mathrm{CO}$ when ventricular function is normal or minimally impaired $(16,19-21,34,35,39)$. Notably, both absolute and relative hypovolemia (decrease in Vs) trigger central and peripheral sympathetically mediated compensatory mechanisms $(19,38)$. Subsequent activation of alpha-1 receptors in the venous vasculature decreases venous capacitance, aiding in the maintenance of MCFP, venous return and CO by shifting blood from Vus to Vs $(24,27,40,41)$. A compensatory decrease in splanchnic blood volume, for example, has been shown to increase
Vs by as much as $10-15 \mathrm{~mL} / \mathrm{kg}$ in hemorrhaged dogs $(25,28,31)$. Importantly, the recruitment (redistribution) of blood from splanchnic and other blood reservoirs (e.g., spleen, lung) may be impaired in animals that are septic, acidotic, hypothermic, aged, or are intolerant of recommended amounts of anesthetic drugs $(17,18)$.

\section{HYPOVOLEMIA}

Hypovolemia is categorized as either absolute or relative. Absolute hypovolemia (i.e., reduction in total circulating blood volume) is either controlled (hemorrhage that has been stopped) or uncontrolled (hemorrhage that has not stopped) and implies the loss of blood, plasma or water from the vascular compartment. Absolute hypovolemia can be conceptualized as a decrease in blood volume relative to a normally sized vascular compartment (Figure 3). Alternatively, relative hypovolemia implies a normal, or possibly increased, blood volume that is not adequate to fill the vascular compartment because the volume (capacity) of the vascular compartment has increased. Hypovolemia from any cause can reduce venous return, $\mathrm{CO}$ and arterial blood pressure, regardless of whether or not compensatory mechanisms are inadequate or impaired, thereby limiting tissue perfusion and DO2 to tissues $(15,16)$. Severe hypovolemia leads to the development of oxygen debt and is directly correlated with lactic acidemia and mortality $(42,43)$. Vasodilation, predominantly venodilation, is an important cause of relative hypovolemia produced by anesthetic drugs and can be exacerbated in sick, septic, hypothermic, or aged animals. Relative hypovolemia frequently contributes to low $\mathrm{CO}$ and hypotension during anesthesia and is a more frequent, insidious, and occult mechanism responsible for cardiovascular collapse and death than decreases in HR and cardiac function typically emphasized as the primary reasons for anesthesia-related adverse events $(10-14,17)$.

\section{CAUSES OF RELATIVE HYPOVOLEMIA}

The principal cause for relative hypovolemia is vasodilation, especially venodilation. Vasodilation during anesthesia is a natural consequence of (1) drug toxicity (e.g., sensitivity to anesthetic drugs or anesthetic overdose), (2) impairment or loss of compensatory mechanisms, (3) coexisting or induced metabolic $(\mathrm{pH}<7.15)$ or respiratory $(\mathrm{PaCO} 2>80 \mathrm{~mm} \mathrm{Hg})$ acidosis; or concurrent, (4) traumatic or surgically induced inflammation, (5) sepsis, (6) cardiogenic shock, and (7) hypothermia. Multiple cellular mechanisms have been implicated in the development of vasodilation and vasodilatory shock that include: a decrease in L-type calcium channel ion transport or myofilament sensitivity to calcium, activation of vascular smooth muscle ATP-sensitive potassium channels ( $K_{\mathrm{ATP}}$ channels), excess production of the inducible form of nitric oxide (iNOS; e.g., sepsis), and deficiency of the hormone vasopressin (Table 1) $(18,44,45)$. Tissue ischemia and/or hypoxia increase intracellular hydrogen ion concentration and decrease cellular ATP production activating $\mathrm{K}_{\text {ATP }}$ channels resulting in smooth muscle hyperpolarization and vasodilation. Sepsis increases the synthesis of nitric oxide due to the increased expression of iNOS synthase and cGMP generation, resulting in 


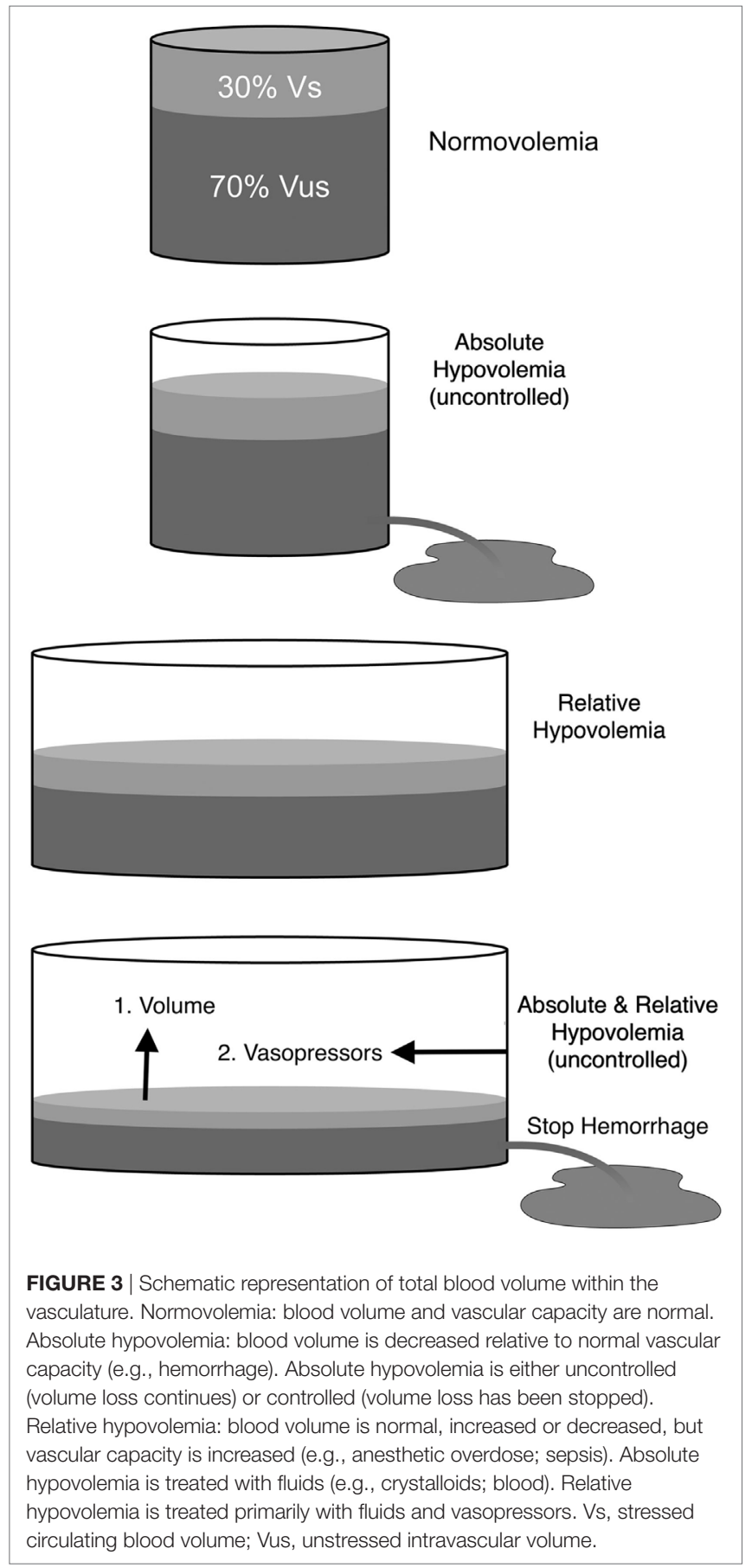

vasorelaxation and resistance to vasoactive drugs (e.g., dopamine, norepinephrine, vasopressin). The combined effects of ischemiainduced acidosis and production of vasodilatory prostaglandins (e.g., PGI2, PGE1, synthetic prostacyclin), activation of $\mathrm{K}_{\mathrm{ATP}}$ channels, and the production of iNOS in animals that are septic or have chronic heart failure, in conjunction with the confounding effects of acidosis and hypothermia, create an ideal environment for vasodilatation, relative hypovolemia and vascular hyporesponsiveness or refractoriness to fluid administration and the administration vasoactive compounds (46-48).
TABLE 1 | General and cellular mechanisms responsible for anesthesiaassociated relative hypovolemia.

Decreased central sympathetic output

Decreased cardiovascular reflex responses

Decreased baroreceptor reflex activity

Decreased VSM contractile response or sensitivity to:

Neurohumoral and adrenoceptor agonists (e.g., norepinephrine)

Depressed mechanisms regulating VSM cytosolic $\mathrm{Ca}^{2+}$

Reduced VSM intracellular $\mathrm{Ca}^{2+}$ concentration

Reduced VSM L-type calcium channel ion transport

Reduced VSM myofilament sensitivity to calcium

Activation of $\mathrm{K}^{+} \mathrm{ATP}$ channels

VSM, vascular smooth muscle; ATP, adenosine triphosphate.

\section{ANESTHETIC MECHANISMS RESPONSIBLE FOR RELATIVE HYPOVOLEMIA}

Almost all drugs that produce anesthesia endanger cardiovascular stability by producing dose-dependent impairment of cardiac function, vascular reactivity and compensatory autoregulatory responses (Table 2) (17). Most produce some impairment of ventricular function, vascular tone and inhibit central or peripheral sympathetic ganglionic transmission of barostatic control when administered at clinically relevant doses (49-52). All but one (i.e., ketamine) are known to modify multiple vasoregulatory mechanisms, leading to a differential reduction in vascular contractile responses, redistribution of blood flow, and increases in vascular capacitance primarily by inhibition of sympathetic nervous system activity and depression of adrenergic neurotransmission and baroreceptor reflex sensitivity (49-54). Venodilation is an important component of the vascular vasodilatory effects of both injectable (e.g., propofol) and inhalant (e.g., isoflurane) general anesthetics (Table 2) (47-53, 55). Importantly, most hypnotic (GABA-A agonist) intravenous anesthetics generally exert important vascular actions following bolus IV injections, while volatile anesthetics produce vasodilatory effects at clinically relevant concentrations (44). Therapeutic concentrations of both propofol and isoflurane, for example, have been shown to decrease Vs by increasing venous capacitance, while producing minimal changes in either $\mathrm{CO}$ or systemic vascular resistance $(50,53,56,57)$. The maintenance of normal or near-normal $\mathrm{CO}$ when either drug is administered has been explained by a decrease in the resistance to venous return and slightly improved stroke volume (SV) due to a decrease in afterload (58). In contrast to propofol and isoflurane, both ketamine and etomidate have been shown to produce minimal effects on venous vascular capacitance in normovolemic humans (59, 60). Ketamine decreased venous capacitance in hypovolemic dogs suggesting that it should be considered the drug of choice for induction to anesthesia and as partial intravenous anesthesia in high risk subjects (60). Summarizing, vascular capacitance modulates CO during hemorrhage and acute volume loading (39). Anesthetic drug-induced increases in venous compliance or capacitance predispose to relative hypovolemia and effectively reduce Vs, $\mathrm{CO}$, and $\mathrm{DO} 2$ to tissues, potentially leading to the development of oxygen debt. The combination of relative and absolute 
TABLE 2 | Pharmacologic effects of clinically relevant doses of commonly administered anesthetic drugs. ${ }^{a}$

\begin{tabular}{|c|c|c|c|c|c|c|c|c|c|c|}
\hline Drug & HR & $\begin{array}{c}\text { Arterial } \\
\text { blood } \\
\text { pressure }\end{array}$ & Co & $\begin{array}{c}\text { Cardiac } \\
\text { contractile } \\
\text { force }\end{array}$ & $\begin{array}{l}\text { MSP or } \\
\text { MCFP }\end{array}$ & $\begin{array}{c}\text { Vasomotor } \\
\text { tone }\end{array}$ & $\begin{array}{l}\text { Baroreceptor } \\
\text { reflex activity }\end{array}$ & $\begin{array}{l}\text { Sympathetic } \\
\text { nerve activity }\end{array}$ & $\begin{array}{c}\text { Splanchnic } \\
\text { venous } \\
\text { capacitance }\end{array}$ & $\begin{array}{l}\text { Venous } \\
\text { return }\end{array}$ \\
\hline Inhalant anesthetic & $\uparrow \downarrow \pm$ & $\downarrow \downarrow$ & $\downarrow \downarrow$ & $\downarrow$ & $\downarrow \downarrow$ & $\downarrow \downarrow$ & $\downarrow \downarrow$ & $\downarrow \downarrow$ & $\uparrow \uparrow$ & $\downarrow \downarrow$ \\
\hline \multicolumn{11}{|l|}{ Injectable hypnotic } \\
\hline Propofol & $\pm \downarrow$ & $\downarrow \downarrow$ & $\downarrow$ & $\downarrow$ & $\downarrow$ & $\downarrow$ & $\downarrow$ & $\downarrow$ & $\uparrow \uparrow$ & $\downarrow \downarrow$ \\
\hline Etomidate & \pm & $\downarrow$ & $\downarrow$ & $\downarrow$ & $\pm \downarrow$ & $\pm \downarrow$ & $\pm \downarrow$ & $\pm \downarrow$ & $\uparrow$ & $\pm \downarrow$ \\
\hline Barbiturate & $\pm \uparrow$ & \pm & $\downarrow$ & $\downarrow$ & $\pm \downarrow$ & $\downarrow$ & $\downarrow$ & $\downarrow$ & $\uparrow$ & $\downarrow$ \\
\hline Neurosteriod & $\pm \downarrow$ & $\downarrow$ & $\downarrow$ & $\pm \downarrow$ & $\pm \downarrow$ & $\pm \downarrow$ & $\downarrow$ & $\downarrow$ & $\uparrow$ & $\downarrow$ \\
\hline Chloralose & $\downarrow$ & \pm & \pm & \pm & \pm & \pm & \pm & \pm & \pm & \pm \\
\hline \multicolumn{11}{|l|}{ Disociative } \\
\hline Ketamine & $\uparrow$ & $\uparrow$ & $\uparrow \pm$ & $\uparrow \pm$ & -- & -- & -- & $--\uparrow$ & -- & -- \\
\hline Tiletamine & $\uparrow$ & $\uparrow$ & $\uparrow \pm$ & $\uparrow \pm$ & -- & -- & -- & $--\uparrow$ & -- & -- \\
\hline \multicolumn{11}{|l|}{ Opioid } \\
\hline Morphine & $\downarrow$ & $--\downarrow$ & $--\downarrow$ & $--\downarrow$ & -- & -- & $--\downarrow$ & $--\downarrow$ & -- & $--\downarrow$ \\
\hline Hydromorphone & $\downarrow$ & $--\downarrow$ & $--\downarrow$ & $--\downarrow$ & -- & -- & $--\downarrow$ & $--\downarrow$ & -- & $--\downarrow$ \\
\hline Fentanyl & $\downarrow$ & $--\downarrow$ & $--\downarrow$ & $--\downarrow$ & -- & -- & $--\downarrow$ & $--\downarrow$ & -- & $--\downarrow$ \\
\hline Alpha-2 agonist & $\downarrow \downarrow$ & $\uparrow \rightarrow \downarrow$ & $\downarrow \downarrow$ & $--\downarrow$ & $\uparrow \rightarrow \downarrow$ & $\uparrow \rightarrow \downarrow$ & $--\downarrow$ & -- & $\downarrow \rightarrow \uparrow$ & $\uparrow \rightarrow \downarrow$ \\
\hline \multicolumn{11}{|l|}{ Benzodiazepine } \\
\hline $\begin{array}{l}\text { Diazepam } \\
\text { Midazolam }\end{array}$ & -- & -- & $--\downarrow$ & -- & $--\downarrow$ & $--\downarrow$ & -- & $--\downarrow$ & $--\downarrow$ & $--\downarrow$ \\
\hline \multicolumn{11}{|l|}{ Phenothiazine } \\
\hline Acepromazine & $\pm \downarrow$ & $\downarrow$ & $--\downarrow$ & $--\downarrow$ & $\downarrow$ & $\downarrow$ & $\downarrow$ & $\downarrow$ & $\uparrow$ & $\downarrow$ \\
\hline \multicolumn{11}{|l|}{ Local anesthetics } \\
\hline Lidocaine & $\pm \uparrow$ & $\downarrow$ & $--\downarrow$ & $--\downarrow$ & $\downarrow$ & $\downarrow$ & -- & $\downarrow$ & $\uparrow$ & $\downarrow$ \\
\hline Bupivacaine & $\pm \uparrow$ & $\downarrow$ & $--\downarrow$ & $--\downarrow$ & $\downarrow$ & $\downarrow$ & -- & $\downarrow$ & $\uparrow$ & $\downarrow$ \\
\hline
\end{tabular}

${ }^{a}$ Clinically relevant dosages are generally equal to or less than those recommended by the manufacturer. Idealized effects expected from normal, healthy humans and animals; $\uparrow$, increase; $\downarrow$, decrease; \pm , increase or decrease; --, little or no change; $\uparrow \rightarrow \downarrow$, increase followed by decrease; $\downarrow \rightarrow \uparrow$, decrease followed by increase. Data compiled from unpublished data (Muir WW, Del Rio CL, Ueyama Y. The effects of anesthetic drugs on mean circulatory filling pressure in isoflurane anesthetized dogs. (2015). Unpublished manuscript.) and (35, 39, 49, 51-53, 57, 61-78).

HR, heart rate; CO, cardiac output.

hypovolemia during anesthesia and surgery in physiologically compromised animals is particularly troublesome, since some animals may rapidly develop irreversible and refractory shock after the loss of relatively small amounts of blood $(5-10 \mathrm{~mL} / \mathrm{kg})$ (Figure 2).

\section{CONSIDERATIONS ON MONITORING AND TREATMENT OF RELATIVE HYPOVOLEMIA}

Identifying and treating relative hypovolemia and tissue hypoperfusion may pose a challenge to the anesthesiologist. During anesthesia, maintenance or prompt reestablishment of appropriate DO2 to all tissues is a main concern (17). Effective circulatory volume, cardiac filling, global, regional and microcirculatory flow, and adequate perfusion pressure are all important elements to consider $(79,80)$.

Presently, perioperative monitoring is largely based on macrocirculatory variables, which may fail to detect relative hypovolemia (81-85). Indeed, despite the recognition of their importance, bedside determination of absolute volemia, monitoring of venous hemodynamics or of microhemodynamics remain cumbersome at best (15). Sophisticated methods for assessment of systemic vascular compliance and Vs have been proposed, but such techniques are yet to be fully validated, particularly in patients with severely compromised vascular tone or receiving vasoactive drugs (86). Therefore, dynamic assessment of a combination of variables along the hemodynamic circuit is helpful for deciphering ongoing processes.

Selection of monitoring procedures depends on a number of factors involving available technology and resources, the anesthesiologist's familiarity with each technique, patient status, and the surgical or medical procedure being performed. In this regard, continuous clinical reassessment of patient status and anesthetic depth remain important tools that should be applied to all (87). Adding to this, standard hemodynamic and global perfusion monitoring of HR and rhythm, arterial pressures, pulse oximetry, expired gases including end-tidal carbon dioxide and inhalant anesthetic concentrations, arterial blood gases, and lactate, offer a wealth of information, particularly when monitored and interpreted collectively and trended over time (82, 87-90). Of note, ongoing perfusion and oxygenation deficits may occur even when blood pressure is considered normal, and urinary output has been shown to bear limited relation with blood volume, effective blood flow, or renal function during anesthesia (91-93).

Conceptually, CVP is an easily obtainable surrogate to right atrial pressure, capable of providing insights into the interaction between venous return and cardiac function (94). As a single numerical value, it provides limited information, but when 
appropriately used and interpreted, within the clinical and interventional context, in combination with static and dynamic variables (and especially CO or SV, if available), it may add valuable information about a patient's condition, particularly when values are outside the normal range, or when extreme, unpredicted, or seemingly paradoxical changes occur, related or not with therapeutic interventions $(15,21,87,94-96)$. An excessively high CVP, for instance, may be indicative of right heart failure, increased pulmonary vascular resistance, or volume overload (87). Still, it has been argued in humans that, while a normal CVP is close to zero and the pressure gradient produced by a normal MCFP 8-10 $\mathrm{mmHg}$ promotes venous return, any sufficient increase in CVP and/or fall in MCFP may reduce venous return and SV (96). Indeed, elevated CVP has been associated with impairment of microcirculatory flow and acute kidney injury in critical patients $(90,96,97)$. Although not a perfect surrogate for mixed venous oxygen saturation, central venous access offers the possibility of central venous oxygen saturation $(\mathrm{ScvO} 2)$ attainment, in addition to the determination of venoarterial difference in $\mathrm{PCO} 2$ $(\mathrm{Pv}-\mathrm{aCO} 2)$. Combined with plasma lactate levels, ScvO2 and $\mathrm{Pv}-\mathrm{aCO} 2$ offer important information regarding the patient's status, enabling inferences regarding $\mathrm{CO}$ and the presence of dysoxia, sepsis and/or anemia $(87,98)$.

Measurement of SV and CO is uncommon in veterinary medicine, and is typically reserved for high-risk or critical patients, particularly those refractory to initial therapy $(82,87)$. Recent reviews have emphasized the limited research validating each method in the veterinary clinical setting, in addition to possible logistic and cost-related considerations (99-101). While several studies have investigated the use of indicator dilution (e.g., using pulmonary artery catheter thermodilution or lithium dilution $\mathrm{CO}$ ), and echocardiography-based methods for determining $\mathrm{CO}$ in different species, these technologies remain impractical in clinical practice (102-110). Of note, echocardiography/Dopplerderived measurements are less invasive, offer unique information on cardiac structure and function, and may offer good estimation of hemodynamic data, but are largely operator-dependent, requiring specialized training and costly equipment $(82,99,111$, 112).

With the aim of sustaining effective circulatory volume, microcirculatory flow and perfusion, the anesthesiologist must assess the appropriateness of fluid administration for each individual patient (summarized by the mnemonic CIT TAIT: context, indication, targets, timing, amount, infusion strategy, and type of fluid) (113), followed by possible use, timing and choice of alternate or ancillary therapy based on vasoactive (pressors, dilators) and/or inotropic support (80, 83, 87, 92, 93, 96, 113-120).

In the context of decreased effective circulating blood volume related to anesthesia and surgical trauma, fluids are generally proposed as a first line therapy, aiming to increase plasma volume, MCFP and the pressure gradient for venous return (83). However, not all patients respond to fluid administration with an increase SV and/or CO (i.e., fluid or preload responsiveness) (121). Beyond fluid dynamics, anesthetic agents and depth, mechanical ventilation (MV), blood flow distribution, endothelial function, integrity of the glycocalyx, and right and left ventricular status all play critical roles in this response $(17,83,113,121-124)$. The question of how to optimize preload, afterload, and contractility remains haunted by the recognition that: both insufficient and excess fluids may result in perfusion deficits and perioperative morbidity; premature or incorrect employment of pressors may also promote further microcirculatory compromise by hindering adequate flow and DO2; and inotropes should be judiciously employed, with guidelines recommending their use only when monitored cardiac function is accompanied by low $\mathrm{CO}$ and signs of hypoperfusion despite preload optimization $(80,82,83,85,92$, 93, 96, 125, 126).

Newer evidence and monitoring options for fluid resuscitation suggest that formulas for replacement and maintenance should be reexamined (127). Among many proposed strategies (e.g., "liberal," "restrictive," "zero-balance," "dynamic fluid balance," and "goal-directed" therapies), a universal algorithm accounting for all possible patient-case combinations remains unrealistic. Current recommendations propose a preplanned approach, tailored to each patient, that employs fluids only on clear indication $(83,92,93,113,125,127-131)$. To this end, functional hemodynamics, using dynamic indices such as systolic pressure variation (SPV), pulse pressure variation (PPV), stroke volume variation (SVV), plethysmographic variability index, aortic flow peak velocity variation ( $\Delta$ Vpeak), and caudal vena cava distensibility index (CVCDI), have demonstrated promise in predicting preload responsiveness and help guide fluid therapy (82, 83, 92, 121, 132-137).

Comprehensive studies, meta-analyses, and reviews are available that elaborate on use of dynamic indices to guide fluid therapy (121, 137-139). Among important highlights, full awareness of all mechanisms and limitations pertaining to each is essential. For instance, many of these methods require MV within very specific settings, and without breathing efforts or arrhythmias during the measurement period $(140,141)$. Patient cardiovascular and pulmonary status, and particularities of surgical interventions, are also important factors that impact cardiopulmonary interactions and related pressure gradients $(121,132-134,136,137$, 141-145). Spontaneous breathing, right ventricular (RV) failure, and increased RV afterload have been associated with falsepositive results for PPV and SVV (i.e., elevated values not related to preload responsiveness) $(95,146-150)$. False-negative results have been observed with insufficient tidal volumes $(\mathrm{Vt})$, decreased lung compliance, and increased vascular compliance $(95,141,144$, 151-153). Other conditions possibly altering cutoff values or compromising their effectiveness are elevated positive end-expiratory pressure, increased Vt, changes in vascular tone, increased abdominal pressure, and changes in chest wall compliance (Table 3) (111, $118,140,142,154-159)$. It is important to note that clinical use of these indices must be investigated in detail, in each species, before translation into clinical practice is feasible. For example, does the dogs' greater chest wall compliance relative to lung compliance impact predictive and cutoff values for each dynamic index (160-162). Lower HR and respiratory rates in horses may also pose limitations (140). Among veterinary-pertinent studies $(105,118,122,160-173)$, a recent investigation with hypotensive dogs found PPV $\geq 15 \%$ had $50 \%$ sensitivity and $96 \%$ specificity in predicting preload responsiveness, further estimating PPV $\geq 19.5$ for $100 \%$ sensitivity (76\% specificity) (171). Another investigation 
TABLE 3 | Factors potentially interfering with PPV and SW. ${ }^{a}$

Spontaneous breathing

Cardiac arrhythmias

Tidal volume ( $\mathrm{t} t$, insufficient, excessive)

Elevated positive end-expiratory pressure

Inspiratory to expiratory ratio

Heart rate to respiratory rate ratio

Lung compliance

Chest wall compliance (including open chest)

Increased right ventricular afterload

Increased intraabdominal pressure

Right and/or left ventricular failure

Increased vascular compliance

Changes in vascular tone

${ }^{a}$ Refer text for details.

PPV, pulse pressure variation; SW, stroke volume variation.

with healthy dogs disclosed cutoff values for $\Delta$ VPeak $\geq 9.4 \%(89 \%$ sensitivity, $100 \%$ specificity), SPV $\geq 6.7 \%$ (78\% sensitivity, $93 \%$ specificity), and CVCDI $\geq 24 \%$ (78\% sensitivity, $73 \%$ specificity), as being predictive of preload responsiveness (172). These promising results warrant further investigations under different clinical and operative scenarios. A concept to be kept in mind, however, is that, even when potentially preload-responsive, the assessment of whether fluids are actually needed, tolerated, or the best management for the condition requires comprehensive clinical judgment, considering the patient's pathophysiological status $(81,82,85,113,174,175)$. Dynamic indices may, nevertheless, offer an additional piece of information to help optimize fluid therapy and further aid decisions targeting use and timing of ancillary or alternate therapeutic interventions (176).

Species-specific clinical trials investigating the efficacy and safety of IV fluid resuscitation are woefully underrepresented in the veterinary literature $(83,87,124,174,177,178)$. Those that do exist are frequently poorly designed, uncontrolled, and underpowered (117). Even fewer studies have focused on the volume kinetics of IV fluids for the treatment of relative hypovolemia associated with injectable or inhalant anesthetic protocols. One study in isoflurane (3\%) anesthetized dogs demonstrated that $80 \mathrm{~mL} / \mathrm{kg}$ of a balanced electrolyte solution (Plasmalyte-A) produced no effect on arterial blood pressure, SV or CO until the inhalant anesthetic concentration was reduced to $1.6 \%$ (122) suggesting that IV fluid therapy may be useless as a treatment for anesthetic-associated relative hypovolemia. Another investigation in hypotensive isoflurane anesthetized dogs concluded that arterial blood pressure measurements were a poor predictor of the hemodynamic response to fluid administration (179). Current suggested guidelines for dogs, cats, and horses have, for the most part, been adopted from experimental studies in rodents, dogs, and pigs, volume kinetic studies conducted in sheep and humans, and clinical trials or meta-analyses completed in humans (180-200). These experimental and clinical studies suggest that fluid choice, optimal fluid volumes $(\mathrm{mL} / \mathrm{kg})$, and the rate of fluid administration $(\mathrm{mL} / \mathrm{kg} / \mathrm{min}$ or $\mathrm{h})$ are context-sensitive (i.e., physical condition, age, surgical procedure, anesthetic choice, etc.) and highly likely to be species-dependent, highlighting the importance of personalizing fluid resuscitation protocols. Taken together these studies suggest that: (1) goal-directed fluid therapy is superior to "rules of thumb" (e.g., $3 \mathrm{~mL}$ crystalloid/1 mL blood loss) or standardized formulas $(3-10 \mathrm{~mL} / \mathrm{kg} / \mathrm{h}) ;(2)$ a balanced crystalloid solution (201), is the best first choice fluid unless laboratory data suggest otherwise; (3) monitoring techniques should include at least one validated dynamic index [e.g., PPV $(165,170$, 171, 173)]; (4) an IV fluid bolus should not exceed 20-30 mL/ $\mathrm{kg}$ (199); and (5) maximal rates of fluid administration should range from 0.02 (maintenance) to $1.0 \mathrm{~mL} / \mathrm{kg} / \mathrm{min}$ (resuscitation) during anesthesia (200).

Fluid therapy for the treatment of anesthetic-associated relative hypovolemia and hypotension remains largely ineffective and predisposes to fluid overload $(87,202,203)$. Not unintentionally, CIT TAIT implies an option to "sit tight" and withhold fluids temporarily or longer (113). In this regard, aside from replenishing Vus reserves, fluid administration should aim to restore Vs and target specified hemodynamic improvement, further considering long term (e.g., impact on organ function, ICU days, survival) measurable outcomes $(174,178,204)$. The most appropriate sequence of events to be considered for treating anesthetic-associated hypotension or signs of low blood flow (e.g., prolonged capillary refill time, weak peripheral pulses, increased PPV) during anesthesia should be to: (1) adjust [e.g., stop; reduce, refine, replace: (3R's of anesthesia)] the anesthetic protocol, (2) administer a balanced crystalloid based upon clinical signs and monitoring data, and (3) administer a vasoactive (e.g., norepinephrine, vasopressin) drug for vasodilation or inotropic (e.g., dobutamine) drug for poor cardiac performance (205). All three events may be required simultaneously, especially in high-risk subjects that have already lost blood (>15-20 mL/kg) or are septic (Figure 3). Notably, the volatile anesthetics sevoflurane and isoflurane have been shown to preserve the endothelial glycocalyx against injury in ketamine anesthetized rats (206-209), whereas propofol increases glycocalyx shedding and vascular permeability (210) and excessive fluid administration triggers atrial natriuretic peptide release increasing vascular membrane permeability and interstitial fluid accumulation (202). Dexmedetomidine has been demonstrated to produce protective effects against ischemia-reperfusion injury in heart, kidney, and brain in rodent animal models (211). These beneficial drug-related actions combined with each drug's known effects on MCFP (Table 2) suggest that balanced anesthesia with isoflurane, ketamine, and dexmedetomidine may help to limit the development of anesthetic-associated endothelial glycocalyx injury and relative hypovolemia.

\section{CONCLUSION}

In summary, anesthesia-induced relative hypovolemia remains an underappreciated and often occult cause of poor tissue perfusion. The venous side of the circulation contains the majority of the blood volume and is a pivotal contributor to SV and CO. Vasodilation, particularly venodilation, is a primary cause of relative hypovolemia induced by anesthetic drugs. As with any hypovolemic state, relative hypovolemia may reduce venous return, CO, tissue oxygen delivery, and eventually arterial blood pressure, when compensatory mechanisms are inadequate or impaired. Tissue oxygen debt can lead to significant morbidity and mortality. Conventional, clinical monitoring, and diagnosis 
of relative hypovolemia during anesthesia relies on subjective clinical and objective macrohemodynamic measurements (e.g., CVP; arterial blood pressure), and global perfusion assessments (e.g., capillary refill time and color, blood gases, lactate). Beyond correction of anesthetic plane, drug choice, and ventilation, therapeutic intervention typically consists of fluid administration, vasoactive and/or inotropic agents, seeking to optimize preload, afterload and cardiac function, with the ultimate goal of maintaining or restoring the effective circulatory volume (Vs), and microcirculatory flow. While many current fluid therapy strategies and fluid monitoring techniques remain under active research and debate, intravenous fluid therapy remains a first line therapy. Intravenous fluid therapy should be personalized and tailored to each patient's requirements based upon a clear indication, consideration of potential benefits vs. harms, and objective measures for determining its effects. Variability in current

\section{REFERENCES}

1. Li G, Warner M, Lang BH, Huang L, Sun LS. Epidemiology of anesthesia-related mortality in the United States, 1999-2005. Anesthesiology (2009) 110(4):759-65. doi:10.1097/ALN.0b013e31819b5bdc

2. Haller G, Laroche T, Clergue F. Morbidity in anaesthesia: today and tomorrow. Best Pract Res Clin Anaesthesiol (2011) 25(2):123-32. doi:10.1016/j.bpa. 2011.02.008

3. Cooper JB, Newbower RS, Long CD, McPeek B. Preventable anesthesia mishaps: a study of human factors. 1978. Qual Saf Health Care (2002) 11(3):277-82. doi:10.1136/qhc.11.3.277

4. Steadman J, Catalani B, Sharp CR, Cooper L. Life-threatening perioperative anesthetic complications: major issues surrounding perioperative morbidity and mortality. Trauma Surg Acute Care Open (2017) 2:1-7. doi:10.1136/ tsaco-2017-000113

5. McMillan M, Darcy H. Adverse event surveillance in small animal anaesthesia: an intervention-based, voluntary reporting audit. Vet Anaesth Analg (2016) 43(2):128-35. doi:10.1111/vaa.12309

6. Brodbelt DC, Blissitt KJ, Hammond RA, Neath PJ, Young LE, Pfeiffer DU, et al. The risk of death: the confidential enquiry into perioperative small animal fatalities. Vet Anaesth Analg (2008) 35(5):365-73. doi:10.1111/ j.1467-2995.2008.00397.x

7. Bille C, Auvigne V, Libermann S, Bomassi E, Durieux P, Rattez E. Risk of anaesthetic mortality in dogs and cats: an observational cohort study of 3546 cases. Vet Anaesth Analg (2012) 39(1):59-68. doi:10.1111/j.1467-2995.2011.00686.x

8. Matthews NS, Mohn TJ, Yang M, Spofford N, Marsh A, Faunt K, et al. Factors associated with anesthetic-related death in dogs and cats in primary care veterinary hospitals. J Am Vet Med Assoc (2017) 250(6):655-65. doi:10.2460/ javma.250.6.655

9. Johnston GM, Eastment JK, Wood J, Taylor PM. The confidential enquiry into perioperative equine fatalities (CEPEF): mortality results of phases 1 and 2. Vet Anaesth Analg (2002) 29(4):159-70. doi:10.1046/j.1467-2995.2002. 00106.x

10. Wagner AE. Complications in equine anesthesia. Vet Clin North Am Equine Pract (2008) 24(3):735-52, x. doi:10.1016/j.cveq.2008.10.002

11. Dugdale AH, Taylor PM. Equine anaesthesia-associated mortality: where are we now? Vet Anaesth Analg (2016) 43(3):242-55. doi:10.1111/vaa.12372

12. Mazaferro E, Wagner AE. Hypotension during anesthesia in dogs and cats: recognition, causes, and treatment. Compend Contin Educ Pract Vet North Am Edn (2001) 23(8):728-34.

13. Young SS, Taylor PM. Factors influencing the outcome of equine anaesthesia: a review of 1,314 cases. Equine Vet $J$ (1993) 25(2):147-51. doi:10.111 1/j.2042-3306.1993.tb02926.x

14. Espinosa P, Le Jeune SS, Cenani A, Kass PH, Brosnan RJ. Investigation of perioperative and anesthetic variables affecting short-term survival of horses with small intestinal strangulating lesions. Vet Surg (2017) 46(3):345-53. doi:10.1111/vsu. 12618 practices related to crystalloid or colloid "fluid bolus," "fluid challenge," or assessment of "preload responsiveness" including methods for the assessment of "hemodynamic improvement," in addition to longer term outcomes, preclude comparisons for substantive conclusions (121, 178, 204, 212-216). Recent studies have focused on data for objective characterization of some of these terms, but no consensus has been established (137, 204, 213, 217-219). Continued research is required, specifically focused on veterinary patients (i.e., for each species and in diverse clinical situations) before they can be effectively translated into clinical practice.

\section{AUTHOR CONTRIBUTIONS}

WM originated the concept for the article. JN-M and WM contributed to drafting and reviewing the manuscript.

15. Gelman S. Venous function and central venous pressure: a physiologic story Anesthesiology (2008) 108(4):735-48. doi:10.1097/ALN.0b013e3181672607

16. Reddi BA, Carpenter RH. Venous excess: a new approach to cardiovascular control and its teaching. J Appl Physiol (1985) (2005) 98(1):356-64. doi:10.1152/japplphysiol.00535.2004

17. Wolff CB, Green DW. Clarification of the circulatory patho-physiology of anaesthesia - implications for high-risk surgical patients. Int J Surg (2014) 12(12):1348-56. doi:10.1016/j.ijsu.2014.10.034

18. Landry DW, Oliver JA. The pathogenesis of vasodilatory shock. $N$ Engl J Med (2001) 345(8):588-95. doi:10.1056/NEJMra002709

19. Funk DJ, Jacobsohn E, Kumar A. The role of venous return in critical illness and shock-part I: physiology. Crit Care Med (2013) 41(1):255-62. doi:10.1097/ CCM.0b013e3182772ab6

20. Brengelmann GL. Letter to the editor: why persist in the fallacy that mean systemic pressure drives venous return? Am J Physiol Heart Circ Physiol (2016) 311(5):H1333-5. doi:10.1152/ajpheart.00536.2016

21. Magder S. Volume and its relationship to cardiac output and venous return. Crit Care (2016) 20:271. doi:10.1186/s13054-016-1438-7

22. Folkow B, Mellander S. Veins and venous tone. Am Heart J (1964) 68:397-408. doi:10.1016/0002-8703(64)90308-4

23. Shen T, Baker K. Venous return and clinical hemodynamics: how the body works during acute hemorrhage. Adv Physiol Educ (2015) 39(4):267-71. doi:10.1152/advan.00050.2015

24. Greenway CV, Seaman KL, Innes IR. Norepinephrine on venous compliance and unstressed volume in cat liver. Am J Physiol (1985) 248(4 Pt 2):H468-76.

25. Shoukas AA, Sagawa K. Control of total systemic vascular capacity by the carotid sinus baroreceptor reflex. Circ Res (1973) 33(1):22-33. doi:10.1161/01. RES.33.1.22

26. Hainsworth R, Karim F. Responses of abdominal vascular capacitance in the anaesthetized dog to changes in carotid sinus pressure. J Physiol (1976) 262(3):659-77. doi:10.1113/jphysiol.1976.sp011614

27. Shigemi K, Brunner MJ, Shoukas AA. Alpha- and beta-adrenergic mechanisms in the control of vascular capacitance by the carotid sinus baroreflex system. Am J Physiol (1994) 267(1 Pt 2):H201-10.

28. Rothe CF. Reflex control of veins and vascular capacitance. Physiol Rev (1983) 63(4):1281-342. doi:10.1152/physrev.1983.63.4.1281

29. Ruffolo RR Jr. Distribution and function of peripheral alpha-adrenoceptors in the cardiovascular system. Pharmacol Biochem Behav (1985) 22(5):827-33. doi:10.1016/0091-3057(85)90535-0

30. Guyton AC. Determination of cardiac output by equating venous return curves with cardiac response curves. Physiol Rev (1955) 35(1):123-9. doi:10.1152/ physrev.1955.35.1.123

31. Hainsworth R. Vascular capacitance: its control and importance. Rev Physiol Biochem Pharmacol (1986) 105:101-73. doi:10.1007/BFb0034498

32. Jacob M, Chappell D, Hofmann-Kiefer K, Helfen T, Schuelke A, Jacob B, et al. The intravascular volume effect of Ringer's lactate is below $20 \%$ : a prospective study in humans. Crit Care (2012) 16(3):R86. doi:10.1186/cc11344 
33. Henderson WR, Griesdale DE, Walley KR, Sheel AW. Clinical review: Guyton - the role of mean circulatory filling pressure and right atrial pressure in controlling cardiac output. Crit Care (2010) 14(6):243. doi:10.1186/ cc9247

34. Guyton AC, Lindsey AW, Kaufmann BN. Effect of mean circulatory filling pressure and other peripheral circulatory factors on cardiac output. Am J Physiol (1955) 180(3):463-8.

35. Maas JJ. Mean systemic filling pressure: its measurement and meaning. Neth J Crit Care (2015) 19(1):6-11.

36. Heymans C. Reflexogenic areas of the cardiovascular system. Perspect Biol Med (1960) 3:409-17. doi:10.1353/pbm.1960.0038

37. Kahler RL, Goldblatt A, Braunwald E. The effects of acute hypoxia on the systemic venous and arterial systems and on myocardial contractile force. J Clin Invest (1962) 41:1553-63. doi:10.1172/JCI104612

38. Smith EE, Crowell JW. Influence of hypoxia on mean circulatory pressure and cardiac output. Am J Physiol (1967) 212(5):1067-9.

39. Scott-Douglas NW, Robinson VJ, Smiseth OA, Wright CI, Manyari DE, Smith ER, et al. Effects of acute volume loading and hemorrhage on intestinal vascular capacitance: a mechanism whereby capacitance modulates cardiac output. Can J Cardiol (2002) 18(5):515-22.

40. Schiller AM, Howard JT, Convertino VA. The physiology of blood loss and shock: new insights from a human laboratory model of hemorrhage. Exp Biol Med (Maywood) (2017) 242(8):874-83. doi:10.1177/1535370217694099

41. Ryan KL, Rickards CA, Hinojosa-Laborde C, Cooke WH, Convertino VA. Sympathetic responses to central hypovolemia: new insights from microneurographic recordings. Front Physiol (2012) 3:110. doi:10.3389/fphys.2012.00110

42. Shoemaker WC, Appel PL, Kram HB. Role of oxygen debt in the development of organ failure sepsis, and death in high-risk surgical patients. Chest (1992) 102(1):208-15. doi:10.1378/chest.102.1.208

43. Rixen D, Siegel JH. Bench-to-bedside review: oxygen debt and its metabolic correlates as quantifiers of the severity of hemorrhagic and post-traumatic shock. Crit Care (2005) 9(5):441-53. doi:10.1186/cc3526

44. Scroggin RD Jr, Quandt J. The use of vasopressin for treating vasodilatory shock and cardiopulmonary arrest. J Vet Emerg Crit Care (San Antonio) (2009) 19(2):145-57. doi:10.1111/j.1476-4431.2008.00352.x

45. Jacob M, Chappell D, Becker BF. Regulation of blood flow and volume exchange across the microcirculation. Crit Care (2016) 20(1):319. doi:10.1186/ s13054-016-1485-0

46. Marsh JD, Margolis TI, Kim D. Mechanism of diminished contractile response to catecholamines during acidosis. Am J Physiol (1988) 254(1 Pt 2): $\mathrm{H} 20-7$.

47. Boerma EC, Ince C. The role of vasoactive agents in the resuscitation of microvascular perfusion and tissue oxygenation in critically ill patients. Intensive Care Med (2010) 36(12):2004-18. doi:10.1007/s00134-010-1970-x

48. Ginimuge PR, Jyothi SD. Methylene blue: revisited. JAnaesthesiol Clin Pharmacol (2010) 26(4):517-20.

49. Akata T. General anesthetics and vascular smooth muscle: direct actions of general anesthetics on cellular mechanisms regulating vascular tone. Anesthesiology (2007) 106(2):365-91. doi:10.1097/00000542-200702000-00026

50. Stadnicka A, Stekiel TA, Bosnjak ZJ, Kampine JP. Inhibition by enflurane of baroreflex mediated mesenteric venoconstriction in the rabbit ileum. Anesthesiology (1993) 78(5):928-36. doi:10.1097/00000542-199305000-00018

51. Stekiel TA, Stekiel WJ, Tominaga M, Stadnicka A, Bosnjak ZJ, Kampine JP. Isoflurane-mediated inhibition of the constriction of mesenteric capacitance veins and related circulatory responses to acute graded hypoxic hypoxia. Anesth Analg (1995) 80(5):994-1001. doi:10.1097/00000539-19950500000025

52. Yamazaki M, Stekiel TA, Bosnjak ZJ, Kampine JP, Stekiel WJ. Effects of volatile anesthetic agents on in situ vascular smooth muscle transmembrane potential in resistance- and capacitance-regulating blood vessels. Anesthesiology (1998) 88(4):1085-95. doi:10.1097/00000542-199804000-00030

53. Hoka S, Yamaura K, Takenaka T, Takahashi S. Propofol-induced increase in vascular capacitance is due to inhibition of sympathetic vasoconstrictive activity. Anesthesiology (1998) 89(6):1495-500. doi:10.1097/00000542-19981200000028

54. Sellgren J, Biber B, Henriksson BA, Martner J, Ponten J. The effects of propofol, methohexitone and isoflurane on the baroreceptor reflex in the cat. Acta Anaesthesiol Scand (1992) 36(8):784-90. doi:10.1111/j.1399-6576.1992. tb03565.x
55. Green DW. Cardiac output decrease and propofol: what is the mechanism? Br J Anaesth (2015) 114(1):163-4. doi:10.1093/bja/aeu424

56. Ebert TJ, Muzi M. Propofol and autonomic reflex function in humans. Anesth Analg (1994) 78(2):369-75. doi:10.1213/00000539-199402000-00029

57. Goodchild CS, Serrao JM. Cardiovascular effects of propofol in the anaesthetized dog. Br J Anaesth (1989) 63(1):87-92. doi:10.1093/bja/63.1.87

58. de Wit F, van Vliet AL, de Wilde RB, Jansen JR, Vuyk J, Aarts LP, et al. The effect of propofol on haemodynamics: cardiac output, venous return, mean systemic filling pressure, and vascular resistances. Br J Anaesth (2016) 116(6):784-9. doi:10.1093/bja/aew126

59. Ebert TJ, Muzi M, Berens R, Goff D, Kampine JP. Sympathetic responses to induction of anesthesia in humans with propofol or etomidate. Anesthesiology (1992) 76(5):725-33. doi:10.1097/00000542-199205000-00010

60. Sohn JT, Lee SJ, Hwang KI, Kim SH, Lee HK, Chung YK. Ketamine sodium thiopental venous capacitance in dog. Korean J Anesthesiol (1998) 34:896-903. doi:10.4097/kjae.1998.34.5.896

61. Tyberg JV. How changes in venous capacitance modulate cardiac output. Pflugers Arch (2002) 445(1):10-7. doi:10.1007/s00424-002-0922-x

62. Hirakawa S, Ito H, Kondo Y, Watanabe I, Hiei K, Banno S, et al. The mean circulatory pressure, reproducibility of its measurements and the effect of phenylephrine with a note on the effect of pentobarbital. Jpn Circ J (1975) 39(4):403-9. doi:10.1253/jcj.39.403

63. Stekiel TA, Ozono K, McCallum JB, Bosnjak ZJ, Stekiel WJ, Kampine JP. The inhibitory action of halothane on reflex constriction in mesenteric capacitance veins. Anesthesiology (1990) 73(6):1169-78. doi:10.1097/00000542199012000-00015

64. Arimura H, Hoka S, Bosnjak ZJ, Kampine JP. Alteration of vascular capacitance and blood flow distribution during halothane anesthesia. J Anesth (1994) 8(4):467-71. doi:10.1007/BF02514628

65. Hoka S, Takeshita A, Yamamoto K, Ito N, Yoshitake J. The effects of ketamine on venous capacitance in rats. Anesthesiology (1985) 62(2):145-8. doi:10.1097/00000542-198502000-00009

66. Lehot JJ, Bastien O, Pelissier FT, Villard J, Estanove S. [Vascular effects of ketamine during anesthesia with diazepam and fentanyl]. Ann Fr Anesth Reanim (1992) 11(1):8-11. doi:10.1016/S0750-7658(05)80313-2

67. Cohen RA, Coffman JD. Effect of morphine on limb capacitance and resistance vessels. Clin Sci (Lond) (1981) 60(1):5-9. doi:10.1042/cs0600005

68. Hsu HO, Hickey RF, Forbes AR. Morphine decreases peripheral vascular resistance and increases capacitance in man. Anesthesiology (1979) 50(2):98-102. doi:10.1097/00000542-197902000-00005

69. Zelis R, Mansour EJ, Capone RJ, Mason DT. The cardiovascular effects of morphine. The peripheral capacitance and resistance vessels in human subjects. J Clin Invest (1974) 54(6):1247-58. doi:10.1172/JCI107869

70. Freye E. The effect of fentanyl on the resistance and capacitance vessels of the dog's hindlimb. Arzneimittelforschung (1977) 27(5):1037-9.

71. Henney RP, Vasko JS, Brawley RK, Oldham HN, Morrow AG. The effects of morphine on the resistance and capacitance vessels of the peripheral circulation. Am Heart J (1966) 72(2):242-50. doi:10.1016/0002-8703(66) 90448-0

72. Stick JA, Chou CC, Derksen FJ, Arden WA. Effects of xylazine on equine intestinal vascular resistance, motility, compliance, and oxygen consumption. Am J Vet Res (1987) 48(2):198-203.

73. Hogan QH, Stadnicka A, Bosnjak ZJ, Kampine JP. Effects of lidocaine and bupivacaine on isolated rabbit mesenteric capacitance veins. Reg Anesth Pain Med (1998) 23(4):409-17. doi:10.1097/00115550-19982304000017

74. Ogilvie RI, Zborowska-Sluis D. Effects of nitroglycerin and nitroprusside on vascular capacitance of anesthetized ganglion-blocked dogs. J Cardiovasc Pharmacol (1991) 18(4):574-80. doi:10.1097/00005344-199110000-00014

75. Baraka A, Haroun S, Baroody M, Nawfal M, Sibai A. Action of adrenergic agonists on resistance $\mathrm{v}$ capacitance vessels during cardiopulmonary bypass. J Cardiothorac Anesth (1989) 3(2):193-5. doi:10.1016/S0888-6296(89)92738-5

76. Butterworth JF, Piccione W Jr, Berrizbeitia LD, Dance G, Shemin RJ, Cohn LH Augmentation of venous return by adrenergic agonists during spinal anesthesia. Anesth Analg (1986) 65(6):612-6. doi:10.1213/00000539-19860600000009

77. Arimura H, Bosnjak ZJ, Hoka S, Kampine JP. Catecholamine-induced changes in vascular capacitance and sympathetic nerve activity in dogs. Can J Physiol Pharmacol (1992) 70(7):1021-31. doi:10.1139/y92-141 
78. Thiele RH, Nemergut EC, Lynch C III. The physiologic implications of isolated alpha(1) adrenergic stimulation. Anesth Analg (2011) 113(2):284-96. doi:10.1213/ANE.0b013e3182124c0e

79. Barbee RW, Reynolds PS, Ward KR. Assessing shock resuscitation strategies by oxygen debt repayment. Shock (2010) 33(2):113-22. doi:10.1097/ SHK.0b013e3181b8569d

80. Chawla LS, Ince C, Chappell D, Gan TJ, Kellum JA, Mythen M, et al. Vascular content, tone, integrity, and haemodynamics for guiding fluid therapy: a conceptual approach. Br J Anaesth (2014) 113(5):748-55. doi:10.1093/bja/ aeu298

81. Vincent JL, Rhodes A, Perel A, Martin GS, Della Rocca G, Vallet B, et al. Clinical review: update on hemodynamic monitoring - a consensus of 16 . Crit Care (2011) 15(4):229. doi:10.1186/cc10291

82. Cecconi M, De Backer D, Antonelli M, Beale R, Bakker J, Hofer C, et al. Consensus on circulatory shock and hemodynamic monitoring. Task force of the European Society of Intensive Care Medicine. Intensive Care Med (2014) 40(12):1795-815. doi:10.1007/s00134-014-3525-Z

83. Navarro LH, Bloomstone JA, Auler JO Jr, Cannesson M, Rocca GD, Gan TJ, et al. Perioperative fluid therapy: a statement from the International Fluid Optimization Group. Perioper Med (Lond) (2015) 4:3. doi:10.1186/s13741015-0014-z

84. Bundgaard-Nielsen M, Jorgensen CC, Secher NH, Kehlet H. Functional intravascular volume deficit in patients before surgery. Acta Anaesthesiol Scand (2010) 54(4):464-9. doi:10.1111/j.1399-6576.2009.02175.x

85. Tatara T. Context-sensitive fluid therapy in critical illness. J Intensive Care (2016) 4:20. doi:10.1186/s40560-016-0150-7

86. Maas JJ, Pinsky MR, Aarts LP, Jansen JR. Bedside assessment of total systemic vascular compliance, stressed volume, and cardiac function curves in intensive care unit patients. Anesth Analg (2012) 115(4):880-7. doi:10.1213/ ANE.0b013e31825fb01d

87. Pachtinger GE, Drobatz K. Assessment and treatment of hypovolemic states. Vet Clin North Am Small Anim Pract (2008) 38(3):629-43, xii. doi:10.1016/j. cvsm.2008.01.009

88. Stevenson CK, Kidney BA, Duke T, Snead EC, Mainar-Jaime RC, Jackson ML. Serial blood lactate concentrations in systemically ill dogs. Vet Clin Pathol (2007) 36(3):234-9. doi:10.1111/j.1939-165X.2007.tb00217.x

89. Nel M, Lobetti RG, Keller N, Thompson PN. Prognostic value of blood lactate, blood glucose, and hematocrit in canine babesiosis. J Vet Intern Med (2004) 18(4):471-6. doi:10.1111/j.1939-1676.2004.tb02569.x

90. Rhodes A, Evans LE, Alhazzani W, Levy MM, Antonelli M, Ferrer R, et al. Surviving sepsis campaign: international guidelines for management of sepsis and septic shock: 2016. Intensive Care Med (2017) 43(3):304-77. doi:10.1007/s00134-017-4683-6

91. Alpert RA, Roizen MF, Hamilton WK, Stoney RJ, Ehrenfeld WK, Poler SM, et al. Intraoperative urinary output does not predict postoperative renal function in patients undergoing abdominal aortic revascularization. Surgery (1984) 95(6):707-11.

92. Voldby AW, Brandstrup B. Fluid therapy in the perioperative setting-a clinical review. J Intensive Care (2016) 4:27. doi:10.1186/s40560-016-0154-3

93. Yeager MP, Spence BC. Perioperative fluid management: current consensus and controversies. Semin Dial (2006) 19(6):472-9. doi:10.1111/j.1525139X.2006.00209.X

94. Magder S. Right atrial pressure in the critically Ill: how to measure, what is the value, what are the limitations? Chest (2017) 151(4):908-16. doi:10.1016/ j.chest.2016.10.026

95. Noel-Morgan J, Otsuki DA, Auler JO Jr, Fukushima JT, Fantoni DT. Pulse pressure variation is comparable with central venous pressure to guide fluid resuscitation in experimental hemorrhagic shock with endotoxemia. Shock (2013) 40(4):303-11. doi:10.1097/SHK.0b013e3182a0ca00

96. Marik PE. Iatrogenic salt water drowning and the hazards of a high central venous pressure. Ann Intensive Care (2014) 4:21. doi:10.1186/s13613-014-0021-0

97. Rivers E, Nguyen B, Havstad S, Ressler J, Muzzin A, Knoblich B, et al. Early goal-directed therapy in the treatment of severe sepsis and septic shock. N Engl J Med (2001) 345(19):1368-77. doi:10.1056/NEJMoa010307

98. De Backer D. Detailing the cardiovascular profile in shock patients. Crit Care (2017) 21(Suppl 3):311. doi:10.1186/s13054-017-1908-6

99. Corley KT, Donaldson LL, Durando MM, Birks EK. Cardiac output technologies with special reference to the horse. J Vet Intern Med (2003) 17(3):262-72. doi:10.1111/j.1939-1676.2003.tb02447.x
100. Shih A. Cardiac output monitoring in horses. Vet Clin North Am Equine Pract (2013) 29(1):155-67. doi:10.1016/j.cveq.2012.11.002

101. Marshall K, Thomovsky E, Johnson P, Brooks A. A review of available techniques for cardiac output monitoring. Top Companion Anim Med (2016) 31(3):100-8. doi:10.1053/j.tcam.2016.08.006

102. Mason DJ, O'Grady M, Woods JP, McDonell W. Assessment of lithium dilution cardiac output as a technique for measurement of cardiac output in dogs. Am J Vet Res (2001) 62(8):1255-61. doi:10.2460/ajvr.2001.62.1255

103. Mason DJ, O'Grady M, Woods JP, McDonell W. Comparison of a central and a peripheral (cephalic vein) injection site for the measurement of cardiac output using the lithium-dilution cardiac output technique in anesthetized dogs. Can J Vet Res (2002) 66(3):207-10.

104. LeBlanc NL, Scollan KF, Stieger-Vanegas SM. Cardiac output measured by use of electrocardiogram-gated 64-slice multidector computed tomography, echocardiography, and thermodilution in healthy dogs. Am J Vet Res (2017) 78(7):818-27. doi:10.2460/ajvr.78.7.818

105. Sasaki K, Mutoh T, Mutoh T, Kawashima R, Tsubone H. Electrical velocimetry for noninvasive cardiac output and stroke volume variation measurements in dogs undergoing cardiovascular surgery. Vet Anaesth Analg (2017) 44(1):7-16. doi:10.1111/vaa.12380

106. Beaulieu KE, Kerr CL, McDonell WN. Evaluation of a lithium dilution cardiac output technique as a method for measurement of cardiac output in anesthetized cats. Am J Vet Res (2005) 66(9):1639-45. doi:10.2460/ajvr. 2005.66.1639

107. Beaulieu KE, Kerr CL, McDonell WN. Evaluation of transpulmonary thermodilution as a method to measure cardiac output in anesthetized cats. Can $J$ Vet Res (2009) 73(1):1-6.

108. Shih AC, Queiroz P, Vigani A, Da Cunha A, Pariaut R, Ricco C, et al. Comparison of cardiac output determined by an ultrasound velocity dilution cardiac output method and by the lithium dilution cardiac output method in juvenile horses with experimentally induced hypovolemia. Am J Vet Res (2014) 75(6):565-71. doi:10.2460/ajvr.75.6.565

109. Linton RA, Young LE, Marlin DJ, Blissitt KJ, Brearley JC, Jonas MM, et al. Cardiac output measured by lithium dilution, thermodilution, and transesophageal Doppler echocardiography in anesthetized horses. Am J Vet Res (2000) 61(7):731-7. doi:10.2460/ajvr.2000.61.731

110. Hadian M, Pinsky MR. Evidence-based review of the use of the pulmonary artery catheter: impact data and complications. Crit Care (2006) 10(Suppl 3):S8. doi:10.1186/cc4355

111. Vieillard-Baron A, Prin S, Chergui K, Dubourg O, Jardin F. Echo-Doppler demonstration of acute cor pulmonale at the bedside in the medical intensive care unit. Am J Respir Crit Care Med (2002) 166(10):1310-9. doi:10.1164/ rccm.200202-146CC

112. Levitov A, Frankel HL, Blaivas M, Kirkpatrick AW, Su E, Evans D, et al. Guidelines for the appropriate use of bedsidegeneral and cardiacultrasonography in the evaluation of critically Ill patients-part II: cardiac ultrasonography. Crit Care Med (2016) 44(6):1206-27. doi:10.1097/CCM.0000000000001847

113. van Haren F. Personalised fluid resuscitation in the ICU: still a fluid concept? Crit Care (2017) 21(Suppl 3):313. doi:10.1186/s13054-017-1909-5

114. Butler AL. Goal-directed therapy in small animal critical illness. Vet Clin North Am Small Anim Pract (2011) 41(4):817-38, vii. doi:10.1016/ j.cvsm.2011.05.002

115. Boag AK, Hughes D. Assessment and treatment of perfusion abnormalities in the emergency patient. Vet Clin North Am Small Anim Pract (2005) 35(2):319-42. doi:10.1016/j.cvsm.2004.10.010

116. Singer M, Deutschman CS, Seymour CW, Shankar-Hari M, Annane D, Bauer M, et al. The third international consensus definitions for sepsis and septic shock (Sepsis-3). JAMA (2016) 315(8):801-10. doi:10.1001/jama.2016.0287

117. Muir WW, Ueyama Y, Noel-Morgan J, Kilborne A, Page J. A systematic review of the quality of IV fluid therapy in veterinary medicine. Front Vet Sci (2017) 4:127. doi:10.3389/fvets.2017.00127

118. Nouira S, Elatrous S, Dimassi S, Besbes L, Boukef R, Mohamed B, et al. Effects of norepinephrine on static and dynamic preload indicators in experimental hemorrhagic shock. Crit Care Med (2005) 33(10):2339-43. doi:10.1097/01. CCM.0000182801.48137.13

119. Chen HC, Sinclair MD, Dyson DH. Use of ephedrine and dopamine in dogs for the management of hypotension in routine clinical cases under isoflurane anesthesia. Vet Anaesth Analg (2007) 34(5):301-11. doi:10.1111/ j.1467-2995.2006.00327.x 
120. Lonjaret L, Lairez O, Minville V, Geeraerts T. Optimal perioperative management of arterial blood pressure. Integr Blood Press Control (2014) 7:49-59. doi:10.2147/IBPC.S45292

121. Michard F, Teboul JL. Predicting fluid responsiveness in ICU patients: a critical analysis of the evidence. Chest (2002) 121(6):2000-8. doi:10.1378/ chest.121.6.2000

122. Valverde A, Gianotti G, Rioja-Garcia E, Hathway A. Effects of high-volume, rapid-fluid therapy on cardiovascular function and hematological values during isoflurane-induced hypotension in healthy dogs. Can J Vet Res (2012) 76(2):99-108.

123. Myatra SN, Monnet X, Teboul JL. Use of 'tidal volume challenge' to improve the reliability of pulse pressure variation. Crit Care (2017) 21(1):60. doi:10.1186/s13054-017-1637-x

124. Michard F. Volume management using dynamic parameters: the good, the bad, and the ugly. Chest (2005) 128(4):1902-3. doi:10.1378/chest.128.4.1902

125. Bundgaard-Nielsen M, Secher NH, Kehlet H. 'Liberal' vs. 'restrictive' perioperative fluid therapy - a critical assessment of the evidence. Acta Anaesthesiol Scand (2009) 53(7):843-51. doi:10.1111/j.1399-6576.2009.02029.x

126. Herget-Rosenthal S, Saner F, Chawla LS. Approach to hemodynamic shock and vasopressors. Clin J Am Soc Nephrol (2008) 3(2):546-53. doi:10.2215/ CJN.01820407

127. Holte K, Foss NB, Andersen J, Valentiner L, Lund C, Bie P, et al. Liberal or restrictive fluid administration in fast-track colonic surgery: a randomized, double-blind study. BrJ Anaesth (2007) 99(4):500-8. doi:10.1093/bja/aem211

128. Brandstrup B, Tonnesen H, Beier-Holgersen R, Hjortso E, Ording H, Lindorff-Larsen $\mathrm{K}$, et al. Effects of intravenous fluid restriction on postoperative complications: comparison of two perioperative fluid regimens: a randomized assessor-blinded multicenter trial. Ann Surg (2003) 238(5):641-8. doi:10.1097/01.sla.0000094387.50865.23

129. MacKay G, Fearon K, McConnachie A, Serpell MG, Molloy RG, O’Dwyer PJ. Randomized clinical trial of the effect of postoperative intravenous fluid restriction on recovery after elective colorectal surgery. Br J Surg (2006) 93(12):1469-74. doi:10.1002/bjs.5593

130. Rivers EP. Fluid-management strategies in acute lung injury - liberal, conservative, or both? N Engl J Med (2006) 354(24):2598-600. doi:10.1056/ $\mathrm{NEJMe} 068105$

131. Cuthbertson BH. Goldilocks, elephants, and surgical fluids. Br J Anaesth (2013) 110(1):144-5. doi:10.1093/bja/aes449

132. Feissel M, Michard F, Mangin I, Ruyer O, Faller JP, Teboul JL. Respiratory changes in aortic blood velocity as an indicator of fluid responsiveness in ventilated patients with septic shock. Chest (2001) 119(3):867-73. doi:10.1378/ chest.119.3.867

133. Lopes MR, Oliveira MA, Pereira VO, Lemos IP, Auler JO Jr, Michard F. Goaldirected fluid management based on pulse pressure variation monitoring during high-risk surgery: a pilot randomized controlled trial. Crit Care (2007) 11(5):R100. doi:10.1186/cc6117

134. Auler JO Jr, Galas F, Hajjar L, Santos L, Carvalho T, Michard F. Online monitoring of pulse pressure variation to guide fluid therapy after cardiac surgery. Anesth Analg (2008) 106(4):1201-6. doi:10.1213/01.ane.0000287664.03547.c6

135. Cannesson M, Desebbe O, Rosamel P, Delannoy B, Robin J, Bastien O, et al. Pleth variability index to monitor the respiratory variations in the pulse oximeter plethysmographic waveform amplitude and predict fluid responsiveness in the operating theatre. Br J Anaesth (2008) 101(2):200-6. doi:10.1093/bja/aen133

136. Gan H, Cannesson M, Chandler JR, Ansermino JM. Predicting fluid responsiveness in children: a systematic review. Anesth Analg (2013) 117(6):1380-92. doi:10.1213/ANE.0b013e3182a9557e

137. Monnet X, Marik PE, Teboul JL. Prediction of fluid responsiveness: an update. Ann Intensive Care (2016) 6(1):111. doi:10.1186/s13613-016-0216-7

138. Marik PE, Cavallazzi R, Vasu T, Hirani A. Dynamic changes in arterial waveform derived variables and fluid responsiveness in mechanically ventilated patients: a systematic review of the literature. Crit Care Med (2009) 37(9):2642-7. doi:10.1097/CCM.0b013e3181a590da

139. Yang X, Du B. Does pulse pressure variation predict fluid responsiveness in critically ill patients? A systematic review and meta-analysis. Crit Care (2014) 18(6):650. doi:10.1186/s13054-014-0650-6

140. De Backer D, Taccone FS, Holsten R, Ibrahimi F, Vincent JL. Influence of respiratory rate on stroke volume variation in mechanically ventilated patients. Anesthesiology (2009) 110(5):1092-7. doi:10.1097/ALN.0b013e31819db2a1
141. De Backer D, Heenen S, Piagnerelli M, Koch M, Vincent JL. Pulse pressure variations to predict fluid responsiveness: influence of tidal volume. Intensive Care Med (2005) 31(4):517-23. doi:10.1007/s00134-005-2586-4

142. Reuter DA, Goepfert MS, Goresch T, Schmoeckel M, Kilger E, Goetz AE. Assessing fluid responsiveness during open chest conditions. Br J Anaesth (2005) 94(3):318-23. doi:10.1093/bja/aei043

143. Monge Garcia MI, Gil Cano A, Gracia Romero M. Dynamic arterial elastance to predict arterial pressure response to volume loading in preload-dependent patients. Crit Care (2011) 15(1):R15. doi:10.1186/cc9420

144. Myatra SN, Prabu NR, Divatia JV, Monnet X, Kulkarni AP, Teboul JL. The changes in pulse pressure variation or stroke volume variation after a "tidal volume challenge" reliably predict fluid responsiveness during low tidal volume ventilation. Crit Care Med (2017) 45(3):415-21. doi:10.1097/ CCM.0000000000002183

145. Pinsky MR. Defining the boundaries of preload responsiveness at the bedside. Pediatr Crit Care Med (2015) 16(1):82-3. doi:10.1097/PCC. 0000000000000291

146. Michard F, Boussat S, Chemla D, Anguel N, Mercat A, Lecarpentier Y, et al. Relation between respiratory changes in arterial pulse pressure and fluid responsiveness in septic patients with acute circulatory failure. Am J Respir Crit Care Med (2000) 162(1):134-8. doi:10.1164/ajrccm.162.1.9903035

147. Vieillard-Baron A, Chergui K, Augarde R, Prin S, Page B, Beauchet A, et al. Cyclic changes in arterial pulse during respiratory support revisited by Doppler echocardiography. Am J Respir Crit Care Med (2003) 168(6):671-6. doi:10.1164/rccm.200301-135OC

148. Vieillard-Baron A, Chergui K, Rabiller A, Peyrouset O, Page B, Beauchet A, et al. Superior vena caval collapsibility as a gauge of volume status in ventilated septic patients. Intensive Care Med (2004) 30(9):1734-9. doi:10.1007/ s00134-004-2361-y

149. Mahjoub Y, Pila C, Friggeri A, Zogheib E, Lobjoie E, Tinturier F, et al. Assessing fluid responsiveness in critically ill patients: false-positive pulse pressure variation is detected by Doppler echocardiographic evaluation of the right ventricle. Crit Care Med (2009) 37(9):2570-5. doi:10.1097/ CCM.0b013e3181a380a3

150. Wyler von Ballmoos M, Takala J, Roeck M, Porta F, Tueller D, Ganter CC, et al. Pulse-pressure variation and hemodynamic response in patients with elevated pulmonary artery pressure: a clinical study. Crit Care (2010) 14(3):R111. doi:10.1186/cc9060

151. Lakhal K, Ehrmann S, Benzekri-Lefevre D, Runge I, Legras A, Dequin PF, et al. Respiratory pulse pressure variation fails to predict fluid responsiveness in acute respiratory distress syndrome. Crit Care (2011) 15(2):R85. doi:10.1186/cc10083

152. Lefrant JY, De Backer D. Can we use pulse pressure variations to predict fluid responsiveness in patients with ARDS? Intensive Care Med (2009) 35(6):966-8. doi:10.1007/s00134-009-1479-3

153. Pereira de Souza Neto E, Grousson S, Duflo F, Ducreux C, Joly H, Convert $\mathrm{J}$, et al. Predicting fluid responsiveness in mechanically ventilated children under general anaesthesia using dynamic parameters and transthoracic echocardiography. Br J Anaesth (2011) 106(6):856-64. doi:10.1093/bja/ aer090

154. Michard F, Chemla D, Richard C, Wysocki M, Pinsky MR, Lecarpentier Y, et al. Clinical use of respiratory changes in arterial pulse pressure to monitor the hemodynamic effects of PEEP. Am J Respir Crit Care Med (1999) 159(3):935-9. doi:10.1164/ajrccm.159.3.9805077

155. Renner J, Gruenewald M, Quaden R, Hanss R, Meybohm P, Steinfath M, et al. Influence of increased intra-abdominal pressure on fluid responsiveness predicted by pulse pressure variation and stroke volume variation in a porcine model. Crit Care Med (2009) 37(2):650-8. doi:10.1097/ CCM.0b013e3181959864

156. de Waal EE, Rex S, Kruitwagen CL, Kalkman CJ, Buhre WF. Dynamic preload indicators fail to predict fluid responsiveness in open-chest conditions. Crit Care Med (2009) 37(2):510-5. doi:10.1097/CCM.0b013e3181958bf7

157. Jacques D, Bendjelid K, Duperret S, Colling J, Piriou V, Viale JP. Pulse pressure variation and stroke volume variation during increased intra-abdominal pressure: an experimental study. Crit Care (2011) 15(1):R33. doi:10.1186/ cc9980

158. Mallat J, Lemyze M, Thevenin D. Ability of respiratory pulse pressure variation to predict fluid responsiveness in ARDS: still an unanswered question? Crit Care (2011) 15(3):432; author reply 432. doi:10.1186/cc10222 
159. Cannesson M, Le Manach Y, Hofer CK, Goarin JP, Lehot JJ, Vallet B, et al. Assessing the diagnostic accuracy of pulse pressure variations for the prediction of fluid responsiveness: a "gray zone" approach. Anesthesiology (2011) 115(2):231-41. doi:10.1097/ALN.0b013e318225b80a

160. Perel A, Pizov R, Cotev S. Systolic blood pressure variation is a sensitive indicator of hypovolemia in ventilated dogs subjected to graded hemorrhage. Anesthesiology (1987) 67(4):498-502. doi:10.1097/00000542-198710000-00009

161. Szold A, Pizov R, Segal E, Perel A. The effect of tidal volume and intravascular volume state on systolic pressure variation in ventilated dogs. Intensive Care Med (1989) 15(6):368-71. doi:10.1007/BF00261495

162. Klein AV, Teixeira-Neto FJ, Garofalo NA, Lagos-Carvajal AP, Diniz MS, Becerra-Velasquez DR. Changes in pulse pressure variation and plethysmographic variability index caused by hypotension-inducing hemorrhage followed by volume replacement in isoflurane-anesthetized dogs. Am J Vet Res (2016) 77(3):280-7. doi:10.2460/ajvr.77.3.280

163. Berkenstadt H, Friedman Z, Preisman S, Keidan I, Livingstone D, Perel A. Pulse pressure and stroke volume variations during severe haemorrhage in ventilated dogs. Br J Anaesth (2005) 94(6):721-6. doi:10.1093/bja/aei116

164. Kim HK, Pinsky MR. Effect of tidal volume, sampling duration, and cardiac contractility on pulse pressure and stroke volume variation during positive-pressure ventilation. Crit Care Med (2008) 36(10):2858-62. doi:10.1097/ CCM.0b013e3181865aea

165. Fielding CL, Stolba DN. Pulse pressure variation and systolic pressure variation in horses undergoing general anesthesia. J Vet Emerg Crit Care (San Antonio) (2012) 22(3):372-5. doi:10.1111/j.1476-4431.2012.00746.x

166. Rabozzi R, Franci P. Use of systolic pressure variation to predict the cardiovascular response to mini-fluid challenge in anaesthetised dogs. Vet J (2014) 202(2):367-71. doi:10.1016/j.tvjl.2014.08.022

167. Diniz MS, Teixeira-Neto FJ, Candido TD, Zanuzzo FS, Teixeira LR, Klein AV, et al. Effects of dexmedetomidine on pulse pressure variation changes induced by hemorrhage followed by volume replacement in isoflurane-anesthetized dogs. J Vet Emerg Crit Care (San Antonio) (2014) 24(6):681-92. doi:10.1111/ vec. 12246

168. Kawazoe Y, Nakashima T, Iseri T, Yonetani C, Ueda K, Fujimoto Y, et al. The impact of inspiratory pressure on stroke volume variation and the evaluation of indexing stroke volume variation to inspiratory pressure under various preload conditions in experimental animals. J Anesth (2015) 29(4):515-21. doi:10.1007/s00540-015-1995-y

169. Sasaki K, Mutoh T, Mutoh T, Taki Y, Kawashima R. Noninvasive stroke volume variation using electrical velocimetry for predicting fluid responsiveness in dogs undergoing cardiac surgery. Vet Anaesth Analg (2017) 44(4):719-26. doi:10.1016/j.vaa.2016.11.001

170. Endo Y, Tamura J, Ishizuka T, Itami T, Hanazono K, Miyoshi K, et al. Stroke volume variation (SVV) and pulse pressure variation (PPV) as indicators of fluid responsiveness in sevoflurane anesthetized mechanically ventilated euvolemic dogs. J Vet Med Sci (2017) 79(8):1437-45. doi:10.1292/jvms.16-0287

171. Fantoni DT, Ida KK, Gimenes AM, Mantovani MM, Castro JR, Patricio GCF, et al. Pulse pressure variation as a guide for volume expansion in dogs undergoing orthopedic surgery. Vet Anaesth Analg (2017) 44(4):710-8. doi:10.1016/j.vaa.2016.11.011

172. Bucci M, Rabozzi R, Guglielmini C, Franci P. Respiratory variation in aortic blood peak velocity and caudal vena cava diameter can predict fluid responsiveness in anaesthetised and mechanically ventilated dogs. Vet J (2017) 227:30-5. doi:10.1016/j.tvjl.2017.08.004

173. Drozdzynska MJ, Chang YM, Stanzani G, Pelligand L. Evaluation of the dynamic predictors of fluid responsiveness in dogs receiving goal-directed fluid therapy. Vet Anaesth Analg (2018) 45(1):22-30. doi:10.1016/j.vaa. 2017.06.001

174. Magder S. Fluid status and fluid responsiveness. Curr Opin Crit Care (2010) 16(4):289-96. doi:10.1097/MCC.0b013e32833b6bab

175. Magder S. Further cautions for the use of ventilatory-induced changes in arterial pressures to predict volume responsiveness. Crit Care (2010) 14(5):197. doi:10.1186/cc9223

176. Michard F, Richards G, Biais M, Lopes M, Auler JO. Using pulse pressure variation or stroke volume variation to diagnose right ventricular failure? Crit Care (2010) 14(6):451; author reply 451. doi:10.1186/cc9303

177. Davis H, Jensen T, Johnson A, Knowles P, Meyer R, Rucinsky R, et al. 2013 AAHA/AAFP fluid therapy guidelines for dogs and cats. J Am Anim Hosp Assoc (2013) 49(3):149-59. doi:10.5326/JAAHA-MS-5868
178. Glassford NJ, Eastwood GM, Bellomo R. Physiological changes after fluid bolus therapy in sepsis: a systematic review of contemporary data. Crit Care (2014) 18(6):696. doi:10.1186/s13054-014-0696-5

179. Muir WW, Ueyama Y, Pedraza-Toscano A, Vargas-Pinto P, Delrio CL, George RS, et al. Arterial blood pressure as a predictor of the response to fluid administration in euvolemic nonhypotensive or hypotensive isoflurane-anesthetized dogs. J Am Vet Med Assoc (2014) 245(9):1021-7. doi:10.2460/javma.245.9.1021

180. Byers CG. Fluid therapy: options and rational selection. Vet Clin North Am Small Anim Pract (2017) 47(2):359-71. doi:10.1016/j.cvsm.2016.09.007

181. Naumann DN, Beaven A, Dretzke J, Hutchings S, Midwinter MJ. Searching for the optimal fluid to restore microcirculatory flow dynamics after haemorrhagic shock: a systematic review of preclinical studies. Shock (2016) 46(6):609-22. doi:10.1097/SHK.0000000000000687

182. Boller E, Boller M. Assessment of fluid balance and the approach to fluid therapy in the perioperative patient. Vet Clin North Am Small Anim Pract (2015) 45(5):895-915. doi:10.1016/j.cvsm.2015.04.011

183. Mapstone J, Roberts I, Evans P. Fluid resuscitation strategies: a systematic review of animal trials. J Trauma (2003) 55(3):571-89. doi:10.1097/01. TA.0000062968.69867.6F

184. Kramer GC. Hypertonic resuscitation: physiologic mechanisms and recommendations for trauma care. J Trauma (2003) 54(5 Suppl):S89-99. doi:10.1097/01.TA.0000065609.82142.F1

185. Hahn RG. The transfusion trigger in major surgery. Acta Anaesthesiol Scand (2018) 62(2):270. doi:10.1111/aas.13042

186. Hahn RG. Adverse effects of crystalloid and colloid fluids. Anaesthesiol Intensive Ther (2017) 49(4):303-8. doi:10.5603/AIT.a2017.0045

187. Hahn RG. Changing practices of fluid therapy. Acta Anaesthesiol Scand (2017) 61(6):576-9. doi:10.1111/aas.12892

188. Hahn RG. Arterial pressure and the rate of elimination of crystalloid fluid. Anesth Analg (2017) 124(6):1824-33. doi:10.1213/ANE.0000000000002075

189. Li Y, Xiaozhu Z, Guomei R, Qiannan D, Hahn RG. Effects of vasoactive drugs on crystalloid fluid kinetics in septic sheep. PLoS One (2017) 12(2):e0172361. doi:10.1371/journal.pone.0172361

190. Hahn RG, Lyons G. The half-life of infusion fluids: an educational review. Eur J Anaesthesiol (2016) 33(7):475-82. doi:10.1097/EJA.0000000000000436

191. Ho L, Lau L, Churilov L, Riedel B, McNicol L, Hahn RG, et al. Comparative evaluation of crystalloid resuscitation rate in a human model of compensated haemorrhagic shock. Shock (2016) 46(2):149-57. doi:10.1097/ SHK.0000000000000610

192. Hahn RG, Drobin D, Zdolsek J. Distribution of crystalloid fluid changes with the rate of infusion: a population-based study. Acta Anaesthesiol Scand (2016) 60(5):569-78. doi:10.1111/aas.12686

193. Hahn RG. Must hypervolaemia be avoided? A critique of the evidence. Anaesthesiol Intensive Ther (2015) 47(5):449-56. doi:10.5603/AIT.a2015.0062

194. Hahn RG. Why crystalloids will do the job in the operating room. Anaesthesiol Intensive Ther (2014) 46(5):342-9. doi:10.5603/AIT.2014.0058

195. Hahn RG. Haemodilution made difficult. Br J Anaesth (2013) 111(4):679-80. doi:10.1093/bja/aet321

196. Hahn RG. Fluid therapy in uncontrolled hemorrhage - what experimental models have taught us. Acta Anaesthesiol Scand (2013) 57(1):16-28. doi:10.1111/j.1399-6576.2012.02763.x

197. Hahn RG, Lindahl CC, Drobin D. Volume kinetics of acetated Ringer's solution during experimental spinal anaesthesia. Acta Anaesthesiol Scand (2011) 55(8):987-94. doi:10.1111/j.1399-6576.2011.02493.x

198. Hahn RG. Volume kinetics for infusion fluids. Anesthesiology (2010) 113(2):470-81. doi:10.1097/ALN.0b013e3181dcd88f

199. Rochwerg B, Alhazzani W, Sindi A, Heels-Ansdell D, Thabane L, FoxRobichaud A, et al. Fluid resuscitation in sepsis: a systematic review and network meta-analysis. Ann Intern Med (2014) 161(5):347-55. doi:10.7326/ M14-0178

200. Tatara T, Tsunetoh T, Tashiro C. Crystalloid infusion rate during fluid resuscitation from acute haemorrhage. Br J Anaesth (2007) 99(2):212-7. doi:10.1093/bja/aem165

201. Muir W. Effect of intravenously administered crystalloid solutions on acidbase balance in domestic animals. J Vet Intern Med (2017) 31(5):1371-81. doi:10.1111/jvim.14803

202. Claure-Del Granado R, Mehta RL. Fluid overload in the ICU: evaluation and management. BMC Nephrol (2016) 17(1):109. doi:10.1186/s12882-016-0323-6 
203. Benes J, Kirov M, Kuzkov V, Lainscak M, Molnar Z, Voga G, et al. Fluid therapy: double-edged sword during critical care? Biomed Res Int (2015) 2015:729075. doi:10.1155/2015/729075

204. Toscani L, Aya HD, Antonakaki D, Bastoni D, Watson X, Arulkumaran N, et al. What is the impact of the fluid challenge technique on diagnosis of fluid responsiveness? A systematic review and meta-analysis. Crit Care (2017) 21(1):207. doi:10.1186/s13054-017-1796-9

205. Zhang Z, Chen K. Vasoactive agents for the treatment of sepsis. Ann Transl Med (2016) 4(17):333. doi:10.21037/atm.2016.08.58

206. Chen C, Chappell D, Annecke T, Conzen P, Jacob M, Welsch U, et al. Sevoflurane mitigates shedding of hyaluronan from the coronary endothelium, also during ischemia/reperfusion: an ex vivo animal study. Hypoxia (Auckl) (2016) 4:81-90. doi:10.2147/HP.\$98660

207. Li J, Yuan T, Zhao X, Lv GY, Liu HQ. Protective effects of sevoflurane in hepatic ischemia-reperfusion injury. Int J Immunopathol Pharmacol (2016) 29(2):300-7. doi:10.1177/0394632016638346

208. Annecke T, Chappell D, Chen C, Jacob M, Welsch U, Sommerhoff CP, et al. Sevoflurane preserves the endothelial glycocalyx against ischaemiareperfusion injury. Br J Anaesth (2010) 104(4):414-21. doi:10.1093/bja/ aeq019

209. Alphonsus CS, Rodseth RN. The endothelial glycocalyx: a review of the vascular barrier. Anaesthesia (2014) 69(7):777-84. doi:10.1111/anae.12661

210. Lin MC, Lin CF, Li CF, Sun DP, Wang LY, Hsing CH. Anesthetic propofol overdose causes vascular hyperpermeability by reducing endothelial glycocalyx and ATP production. Int J Mol Sci (2015) 16(6):12092-107. doi:10.3390/ ijms 160612092

211. Engelhard K, Werner C, Eberspacher E, Bachl M, Blobner M, Hildt E, et al. The effect of the alpha 2-agonist dexmedetomidine and the N-methyl-Daspartate antagonist $\mathrm{S}(+)$-ketamine on the expression of apoptosis-regulating proteins after incomplete cerebral ischemia and reperfusion in rats. Anesth Analg (2003) 96(2):524-31. doi:10.1097/00000539-200302000-00041

212. Cecconi M, Hofer C, Teboul JL, Pettila V, Wilkman E, Molnar Z, et al. Fluid challenges in intensive care: the FENICE study: a global inception cohort study. Intensive Care Med (2015) 41(9):1529-37. doi:10.1007/s00134-0153850-x
213. Aya HD, Rhodes A, Chis Ster I, Fletcher N, Grounds RM, Cecconi M. Hemodynamic effect of different doses of fluids for a fluid challenge: a quasi-randomized controlled study. Crit Care Med (2017) 45(2):e161-8. doi:10.1097/CCM.0000000000002067

214. Muller L, Toumi M, Bousquet PJ, Riu-Poulenc B, Louart G, Candela D, et al. An increase in aortic blood flow after an infusion of $100 \mathrm{ml}$ colloid over 1 minute can predict fluid responsiveness: the mini-fluid challenge study. Anesthesiology (2011) 115(3):541-7. doi:10.1097/ALN.0b013e318229a500

215. Marik PE. Fluid therapy in 2015 and beyond: the mini-fluid challenge and mini-fluid bolus approach. Br J Anaesth (2015) 115(3):347-9. doi:10.1093/ bja/aev169

216. Biais M, de Courson H, Lanchon R, Pereira B, Bardonneau G, Griton M, et al. Mini-fluid challenge of $100 \mathrm{ml}$ of crystalloid predicts fluid responsiveness in the operating room. Anesthesiology (2017) 127(3):450-6. doi:10.1097/ ALN.0000000000001753

217. Aya HD, Ster IC, Fletcher N, Grounds RM, Rhodes A, Cecconi M. Pharmacodynamic analysis of a fluid challenge. Crit Care Med (2016) 44(5):880-91. doi:10.1097/CCM.0000000000001517

218. Aldrich J. Shock fluids and fluid challenge. In: Silverstein D, Hopper K, editors. Small Animal Critical Care Medicine. St. Louis, USA: Saunders Elsevier (2009).

219. Magder S. Central venous pressure: a useful but not so simple measurement. Crit Care Med (2006) 34(8):2224-7. doi:10.1097/01.CCM.0000227646. 98423.98

Conflict of Interest Statement: The authors declare that the manuscript was written in the absence of any commercial or financial relationships that could be construed as a potential conflict of interest.

Copyright (C) 2018 Noel-Morgan and Muir. This is an open-access article distributed under the terms of the Creative Commons Attribution License (CC BY). The use, distribution or reproduction in other forums is permitted, provided the original author(s) and the copyright owner are credited and that the original publication in this journal is cited, in accordance with accepted academic practice. No use, distribution or reproduction is permitted which does not comply with these terms. 